\title{
Students See the Elephant
}

Joseph W. Gravel, Jr, MD; Stephanie E. Rosener, MD, IBCLC;

Wendy Brooks Barr, MD, MPH, MSCE; Kelly J. Hill, MD

(Fam Med. 2019;51(8):638-40.)

doi: 10.22454/FamMed.2019.280464

n 2004, the same year that the Future of Family Medicine Collaborative considered the state of family medicine and its future direction, John Saultz, MD, and Alan David, MD wrote an essay entitled "Is It Time for a 4-Year Family Medicine Residency?"1 published in this journal.

\begin{abstract}
The elephant in the room ... is whether or not the goals of a family medicine residency can be accomplished in the traditional 36-month curriculum. Discussions of lengthening the residency have usually been brief due to concerns about the substantial logistical challenges involved... Nevertheless, we believe that a serious discussion of lengthening the residency to 4 years should be undertaken immediately and that the future of the discipline could depend on the outcome of such a debate.
\end{abstract}

Many family medicine leaders at the 2011 Family Medicine Working Party Length of Training Summit were understandably concerned about a required 4-year residency's potential negative effect on student interest. The following year, Peter Carek, MD, MS, asked family medicine program directors ${ }^{2}$ whether "increasing the length of training will significantly decrease medical student interest." Notably, more program directors strongly agreed/ agreed (44.8\%) than strongly disagreed/disagreed (30.5\%), with about one-fourth (24.7\%) on the fence.

In the first Accreditation Council for Graduate Medical Education (ACGME) Length of Training Pilot paper to be published, "Effect of Length of Training on Residency Applications and Match Performance in Family Medicine,"3 Eiff and colleagues' results suggest this fear is unfounded. The specialty should no longer consider this concern to be a valid reason for not offering a 4-year residency model if the needs of patients, the evolving training needs of residents, and the specialty's future place in the health care system demand it. Eiff addresses an important question: "If you build it, will they come?" The answer is yes.

This is hard-won knowledge. The Length of Training Pilot experienced challenges from its inception in 2013. The study's request for proposals was announced in the throes of ACGME Milestones implementation, and programs had only a few short months following the announcement to commit to the study and develop proposals. Programs received no funding for developing and implementing study-related curricular changes and no CMS GME funding for PGY-4 residents. The number of programs that stepped up to participate was consequently small, even though more program directors agreed than disagreed that family medicine residency should be 4 years ${ }^{2}$ at the time of the pilot's launch. Four-year pilot programs persevered, made mistakes, identified learning opportunities, and were willing to risk some failures for a greater gain.

Eiff's findings should not be surprising. Students' most important concern when choosing a residency is whether they will be prepared for practice and/or additional training. ${ }^{4}$ This also confirms what has been previously described: lengthening training would have a neutral or positive effect on applicants' interest in family medicine. ${ }^{5,6}$ Unlike previous studies that asked students a theoretical question, Eiff

From the Lawrence Family Medicine Residency, Lawrence, MA (Drs Gravel and Barr); Middlesex Hospital Family Medicine Residency Program, Middletown, CT (Dr Rosener); and MidMichigan Medical Center, Midland, MI (Dr Hill). 
and colleagues' study measures actual student behavior when given the opportunity to choose a 4-year program. We can put unfounded concerns about the effect of increased length of training on student interest aside and focus on the quality of the product. Doing so may serve to increase student interest in family medicine more than focusing primarily on marketing the specialty.

The good news is that students (1) are not simply looking for the least amount of training time possible, and (2) will not run away from family medicine if the specialty decides to offer a longer training period, consistent with the vast majority of other specialty training periods their classmates are choosing.

Eiff's study may be underestimating the positive effects of a 4-year training period on recruitment due to several factors. For all 4 years, programs were recruiting in an environment where 4 years is less known, which makes generalizability difficult. Additionally, most of the 4-year length of training programs' (LOT4) match data is from years where programs were undergoing significant change and uncertainty while building their 4-year residency. This likely negatively impacted recruitment as there were no outcomes to share with applicants. We would like to see this study done from 2017-2020 when LOT4 programs are fully transformed, curricula more established, and some information about graduates of their 4-year curriculum is available.

Analyzing trends about PGY-1 perspectives on residency program selection are somewhat problematic. Eiff notes that more LOT4 residents over time do not think that FM requires 4 years, and that the major driver was more flexibility in training. The limitation of this analysis is that $50 \%$ of the participating residents are from optional 4-year programs, so this does not capture the perspectives of PGY1 residents who have committed to 4 years of training.

Family medicine's long-standing efforts to increase student interest is harmed by the meta-messaging that family medicine requires the least amount of training of any specialty. The vast majority of students entering internal medicine and nearly half entering pediatrics residencies do not ultimately complete their training in three years. ${ }^{11,12}$ All other specialties require longer training periods.
We have listened to hundreds of students interviewing at our 4-year programs during the past 5 years, and have learned:

1. Many students find it counterintuitive that the broadest specialty requires the least amount of training. Compared with the vast majority of their classmates who are signing up for 4 or more years of training, many students see a 3-year training period as an outlier, and not to the good.

2. Although some students who choose family medicine believe they will be content with an outpatient, cognitive-only existence caring for adults, most do not, which is why they are not choosing internal medicine. They seek a broader scope of practice and recognize that this may require a longer training period than internal medicine.

3. Some students are also considering a 4-year medicine-pediatrics residency, but recognize that family medicine residency includes more training in outpatient procedures, behavioral health, women's health, and maternity care. Currently, they need to choose a shorter residency for this additional training-again counterintuitive-suggesting there is something amiss.

4. Students expect standard, not elective training in important new content areas such as point-of-care ultrasound, quality improvement, health information technology, population health, genomics/personalized medicine, and advocacy.

5. Students recognize there is an opportunity for family physicians to assume leadership roles in health systems and to address social determinants of health. They believe enhanced preparation for these roles in a 21st-century residency should be standard, not optional.

When given a 4-year option, students are choosing the "harder road." This is important information! Higher quality generally attracts more consumers, especially ones who have already invested a great deal prior to getting to the buying decision. The additional upfront cost is justified if the quality and utility of the product over time is present. The enhanced curricula in our 4-year programs have enabled not only increased breadth, but also increased depth. Our best hope of achieving 
the quadruple aim is to produce more skilled, broadly-trained graduates.

Other important findings for family medicine will be shared in future papers from the Length of Training Pilot. Fears about programs' financial viability, residents' potential buyer's remorse, and concerns about lack of adequate added value for the additional time investment will be explored, and may also prove to be unfounded.

The "elephant in the room" has grown even larger in size since 2004, and with duty hour restrictions, the room has gotten even smaller. Students are acknowledging the elephant and have put their belief into action for the pilot's 5 years, even when many who practice and/or teach family medicine still do not. For the nation's sake, we need to get more students into the room who are now choosing to go elsewhere-when they would have been, could have been, and should have been outstanding family physicians.

The road-tested blueprints-however imperfect_are now available.

CORRESPONDING AUTHOR: Address correspondence to $\mathrm{Dr}$ Joseph Gravel, Lawrence Family Medicine Residency, 34 Haverhill St, Lawrence, MA 01840. 781-771-8634. 978-687-2106. joegraveljr@gmail.com.

\section{References}

1. Saultz JW, David AK. Is it time for a 4-year family medicine residency? Fam Med. 2004;36(5):363-366.

2. Carek PJ, Peterson L, Shokar NK, Johnson SP, Knoll ME, Mainous AG. GME and primary care workforce. Fam Med. 2012;44(10):712-715.
3. Eiff MP, Ericson A, Uchison EW, et al. A comparison of residency applications and match performance to 3-year versus 4-year family medicine training programs. Fam Med. 2019;51(8):641-648..

4. Phitayakorn R, Macklin EA, Goldsmith J, Weinstein DF. Applicants' self-reported priorities in selecting a residency program. J Grad Med Educ. 2015;7(1):21-26.

5. Smits AK, Walsh E, Ross RG, Gillanders WR, Saultz JW. Residency applicants' perspectives on family medicine residency training length. Fam Med. 2006;38(3):172-176.

6. Duane M, Dovey SM, Klein LS, Green LA. Follow-up on family practice residents' perspectives on length and content of training. J Am Board Fam Pract. 2004;17(5):377-383.

7. Porter S. AAFP Hosts Launch of $25 \times 2030$ Student Choice Collaborative. https://www.aafp.org/news/education-professional-development/20180905twentyfiveby2030.html. Accessed July 2, 2019.

8. Kelly BF, Sicilia JM, Forman S, Ellert W, Nothnagle M. Advanced procedural training in family medicine: a group consensus statement. Fam Med. 2009;41(6):398-404.

9. American Academy of Family Physicians. AAFP Student Influencer Portfolio, AAFP Division of Medical Education. https://www.aafp.org/dam/AAFP/documents/medical education_residency/pre-med/AAFPStudentInterestPortfolio.pdf. Accessed July 2, 2019.

10. Wright KM, Ryan ER, Gatta JL, Anderson L, Clements DS. Finding the perfect match: factors that influence family medicine residency selection. Fam Med. 2016;48(4):279-285.

11. American Board of Internal Medicine. Resident and Fellow Workforce Data: 2016-2017. https://www.abim.org/about/ statistics-data/resident-fellow-workforce-data.aspx. Accessed July 24, 2019

12. American Board of Pediatrics. Pediatric Physicians Workforce Data Book 2017-2018. Chapel Hill, NC: American Board of Pediatrics; 2018. https://www.abp.org/sites/abp/files/pdf/pediatricphysiciansworkforcedatabook2017-2018.pdf. Accessed July 24, 2019

13. Anthony D, White J, Margo K, Tarn DM. Scope of practice and family medicine match rates: results from a CERA survey. Fam Med. 2017;49(3):177-182. 